\title{
Гефан Г.Д. \\ Разъяснение положений теории вероятностей с помощью примеров из жизни и художественной литературы
}

Иркутский государственный университет путей сообщения

(Россия, Иркутск)

doi: 10.18411/trnio-01-2022-133

\section{Аннотация}

На ситуациях, известных из художественной литературы и обычной жизни, иллюстрируются важные положения теории вероятностей, связанные со случайными событиями. Такой подход к обучению, безусловно, способствует пониманию этого непростого материала.

Ключевые слова: вероятность случайного события, условная вероятность, зависимость и независимость событий, вероятность произведения событий.

\section{Abstract}

On situations known from fiction and ordinary life, important provisions of the probability theory associated with random events are illustrated. This approach to teaching certainly contributes to the understanding of this difficult material.

Keywords: the probability of a random event, conditional probability, dependence and independence of events, the probability of the product of events.

Теория вероятностей - один из разделов математики, наиболее тесно примыкающий к гуманитарно-культурной сфере. Желание преподавателя сопроводить обучение этой дисциплине яркими, всем понятными и практически значимыми примерами является естественным и разумным.

В частности, зависимость событий - важнейшее свойство, без правильного понимания которого невозможно усвоить основные теоремы о вероятности. Понятие зависимости событий обычно связывают с так называемой условной вероятностью $P(A \mid B)$ - вероятностью события $A$, вычисленной при условии, что произошло событие $B[1,2]$. Событие $A$ называется зависимым от события $B$, если $P(A \mid B) \neq P(A)$. Вероятность произведения двух событий определяется формулой

$$
P(A B)=P(B) P(A \mid B)=P(A) P(B \mid A) .
$$

Если $P(A \mid B)=P(A)(A$ не зависит от $B)$, то и

$$
P(B \mid A)=P(B) P(A) / P(A)=P(B),
$$

то есть $B$ тоже не зависит от $A$. Таким образом, независимость (как и зависимость) событий взаимна. Вероятность произведения независимых событий

$$
P(A B)=P(A) P(B) .
$$

$\mathrm{C}$ некоторой натяжкой можно сказать, что математическое определение зависимости (и независимости) событий соответствует житейским представлениям об этом понятии. Большая часть аудитории относится с пониманием к утверждению, что не зависят друг от друга результаты бросания двух монет, двух игральных костей, даты рождения двух случайных людей и т.д. Впрочем, кое-кто всё же имеет ошибочные представления о некотором «лимите» наступлений события по принципу «в одну воронку снаряд дважды не попадает».

В качестве примера рассмотрим повесть Эдгара По «Тайна Мари Роже» (1842), входящую в цикл о сыщике-любителе Огюсте Дюпене. С этого цикла, собственно, и начался детективный жанр в мировой литературе. На протяжении повести писатель устами своего 
главного героя много раз говорит о теории вероятностей, которая тогда была относительно молодой наукой, и, в частности, высказывает следующую мысль: длинная цепочка относительно маловероятных событий представляет собой событие крайне маловероятное, почти невозможное. Это совершенно правильное утверждение.

Но вот что он пишет в конце рассказа:

«Обычного читателя почти невозможно убедить, что при игре в кости двукратное выпадение шестерки делает почти невероятным выпадение ее в третий раз... Заурядный интеллект не может этого воспринять, он не может усмотреть, каким образом два броска, принадлежащие уже прошлому, могут повлиять на бросок, существующий еще пока только в будущем. Возможность выпадения шестёрки кажется точно такой же, как и в любом случае... И это представляется настолько очевидным, что всякое возражение обычно встречается насмешливой улыбкой, а отнюдь не выслушивается с почтительным вниманием. Суть скрытой тут ошибки - грубейшей ошибки - я не могу объяснить в пределах места, предоставленного мне здесь, а людям, искушенным в философии, никакого объяснения и не потребуется» [3].

Здесь всё поставлено с ног на голову. Грубейшая ошибка (которую делают неискушённые люди, в том числе, и сам писатель) как раз состоит в том, чтобы считать, что после двух выпавших шестёрок выпадение её в третий раз является маловероятным. Ничего подобного! Эта вероятность равна 1/6, как и при любом другом подбрасывании. Другое дело, что вероятность выпадения трёх шестёрок подряд действительно мала, она составляет 1/6 в 3-й степени, т.е. 1/216. Но знание того факта, что на двух костях выпали шестерки, никак не влияет на вероятность выпадения шестёрки на третьей кости, поскольку речь идёт о независимых событиях. Так что замечательный писатель, родоначальник детективной литературы (сумевший, кстати, в своей повести сделать выводы о реальном деле, которые позже подтвердились), в процитированном выше высказывании заблуждался.

Совершенно иначе обстоит дело, когда речь идёт о событиях зависимых. В романе И. Ильфа и Е. Петрова «Двенадцать стульев» герои знают, что в одном из 12 стульев зашиты бриллианты. Они поочерёдно находят стулья и вскрывают их. В романе есть следующая сцена [4].

«После вскрытия стула Ипполит Матвеевич загрустил.

- Шансы всё увеличиваются, - сказал Остап...»

Найдём вероятности того, что бриллианты оказались бы:

- в первом стуле;

- во втором стуле, если они не были найдены в первом;

- в третьем стуле, если они не были найдены в первом и втором и т.д.

Пусть $A_{1}, A_{2}, \ldots, A_{12}$ - события, состоящие в том, что бриллианты находились в 1-ом, 2-ом, ..., 12-ом стульях, если перенумеровать стулья в порядке их попадания к героям романа. Изначально эти события образуют полную группу несовместных равновозможных событий, так что

$$
P\left(A_{1}\right)=1 / 12, P\left(A_{2}\right)=1 / 12, \ldots, P\left(A_{12}\right)=1 / 12 .
$$

Пусть $P\left(A_{2} \mid \overline{A_{1}}\right)$ - вероятность обнаружения клада во втором стуле при условии, что первый стул оказался пустым. Ясно, что $P\left(A_{2} \mid \overline{A_{1}}\right)=1 / 11$.

Вероятность обнаружения клада в третьем стуле при условии его отсутствия в первых двух стульях $P\left(A_{3} \mid \overline{A_{1}} \cdot \overline{A_{2}}\right)=1 / 10$. (Здесь событие, выступающее в качестве условия, представляет собой произведение событий.)

Продолжать этот ряд вряд ли имеет смысл. Разумеется, Бендер был прав: шансы на успех возрастают с каждой очередной неудачей. Вероятность обнаружения клада в последнем стуле была бы равна единице, если бы к тому времени, когда герои добрались до этого стула, клад не был найден другими людьми. 
Заметим, что $P\left(A_{2} \mid \overline{A_{1}}\right)=1 / 11$, тогда как другая условная вероятность $P\left(A_{2} \mid A_{1}\right)=0$, а безусловная вероятность $P\left(A_{2}\right)=1 / 12$. Это и говорит о зависимости событий.

Другой пример - известная жизненная ситуация, когда несколько участников последовательно тянут спички, одна из которых является короткой. Обычно у студентов не вызывает возражений утверждение, что шансы вытянуть эту короткую спичку априори одинаковы у всех участников, независимо от того, в какой последовательности они тянут спички. А между тем, это не столь уж очевидно и, пожалуй, требует доказательства.

Итак, пусть спички тянут 5 человек; из 5 спичек одна короткая. Первый вытянет короткую спичку с вероятностью $P\left(A_{1}\right)=1 / 5$. Второй - с вероятностью $1 / 4$. Но это после того, как первый вытянул длинную! Изначально же

Для третьего участника

$$
P\left(A_{2}\right)=(4 / 5) \times(1 / 4)=1 / 5 \text {. }
$$

$$
P\left(A_{3}\right)=(4 / 5) \times(3 / 4) \times(1 / 3)=1 / 5
$$

и т.д. Действительно, изначально шансы всех участников одинаковы.

Вместе с тем, кажется, что плохо согласуется с обычным представлением о зависимости следующее важное положение теории вероятностей: два события являются либо взаимно зависимыми, либо взаимно независимыми.

Простой пример: есть «метеозависимые» люди, самочувствие которых зависит от погоды [5], но никто никогда не слышал о том, чтобы погода зависела от здоровья людей. А как же быть, в таком случае, с положением о взаимной зависимости событий? Парадокс!

Но не надо упускать из виду, что в теории вероятностей речь идет не о механизме «причина-следствие», а о зависимости случайных событий. Зависит ли вероятность nеремень nогодbl от самочувствия «метеозависимого» человека? Безусловно, зависит, поскольку плохое самочувствие с некоторой вероятностью может сигнализировать о перемене погоды. Так что это кажущееся противоречие между математикой и «здравым смыслом» довольно легко снимается.

Рассмотрим конкретный пример. Имеем два события: $A$ - плохое самочувствие метеозависимого человека; $B$ - наступление плохой погоды. Допустим, человек неважно себя чувствует в среднем один раз в 5 дней: $P(A)=1 / 5$. Плохая погода наступает в среднем один раз в 3 дня: $P(B)=1 / 3$. Пусть также известно, что при наступлении плохой погоды метеозависимый человек чувствует себя плохо в половине случаев: $P(A \mid B)=1 / 2$. Тот факт, что $P(A \mid B) \neq P(A)$ говорит о зависимости события $A$ от события $B$. При этом вероятность одновременного наступления этих событий равна $P(A B)=P(B) P(A \mid B)=1 / 6$.

Теперь посмотрим на эту ситуацию с другой стороны: $P(A B)=P(A) P(B \mid A)$, откуда $P(B \mid A)=(1 / 6) /(1 / 5)=5 / 6$. Итак, $P(B \mid A) \neq P(B)$, что говорит о зависимости события $B$ от события $A$, как бы ни странно это выглядело на первый взгляд. В данном конкретном случае эта зависимость проявляется в том, что в отсутствие информации о самочувствии метеозависимого человека вероятность плохой погоды равна $1 / 3$, однако при условии его плохого самочувствия эта вероятность возрастает до 5/6. Ещё раз подчеркнём: речь не о том, что самочувствие человека влияет на погоду, а лишь о том, что этот человек является своеобразным барометром, сигнализируя о высокой вероятности ухудшения погоды.

$$
* * *
$$

1. Вентцель, Е. С. Теория вероятностей. - М. : Наука, 1969. - 576 с.

2. $\quad$ Гефан Г.Д. Статистический метод и основы его применения. - Иркутск : Ир-ГУПС, 2003. - 207 с.

3. По, Э.А. Тайна Мари Роже. - М.: Бертельсманн (БММ), 2013. - 112 с.

4. Ильф, И. А., Петров, Е. П. Двенадцать стульев. - М. : Юрайт, 2021. - 292 с.

5. Метеозависимость: что это такое и как с ней жить. - URL: https://meteoagent.com/ru/meteozavisimost (Дата обращения: 06.12.2021). 